\title{
ERRATA
}

\author{
Taxonomic Dissection of the Genus Micrococcus: Kocuria gen. \\ nov., Nesterenkonia gen. nov., Kytococcus gen. nov., \\ Dermacoccus gen. nov., and Micrococcus \\ Cohn 1872 gen. emend. \\ ERKO STACKEBRANDT, CATHRIN KOCH, OXANA GVOZDIAK, \\ AND PETER SCHUMANN \\ DSM-German Collection of Microorganisms and Cell Cultures GmbH, 38124 Braunschweig \\ and 07708 Jena, Germany, and Zabolotny Institute of Microbiology and Virology, \\ National Academy of Sciences of Ukraine, Kiev, 252143 Ukraine
}

Vol. 45, no. 4, p. 682, Abstract, lines 7 to 9: "the genus Kytococcus gen. nov. for Micrococcus nishinomiyaensis, described as Kytococcus nishinomiyaensis comb. nov.; and the genus Dermacoccus gen. nov. for Micrococcus sedentarius, described as Dermacoccus sedentarius comb. nov." should read "the genus Dermacoccus gen. nov. for Micrococcus nishinomiyaensis, described as Dermacoccus nishinomiyaensis comb. nov.; and the genus Kytococcus gen. nov. for Micrococcus sedentarius, described as Kytococcus sedentarius comb. nov."

\section{Moraxella caprae sp. nov., a New Member of the Classical Moraxellae with Very Close Affinity to Moraxella bovis}

ANGELI KODJO, TONE TøNJUM, YVES RICHARD, AND KJELL BøVRE

Ecole Nationale Vétérinaire de Lyon, F-69280 Marcy l'Etoile France, and Kaptein W. Wilhelmsen og Frues Bakteriologiske Institutt, University of Oslo, Rikshospitalet, N-0027 Oslo 1, Norway

Volume 45, no. 3, p. 467, Abstract, last line: "CCUG 33297" should read "CCUG 33296."

Page 471, column 1, line 3 from bottom: "CCUG 33297" should read "CCUG 33296."

\author{
Aeromonas encheleia sp. nov., Isolated from European Eels \\ CONSUELO ESTEVE, M. CARMEN GUTIÉRREZ, AND ANTONIO VENTOSA \\ Departamento de Microbiología y Ecología, Facultad de Ciencias Biológicas, \\ Universitat de Valéncia, E-46100 Burjasot (Valencia), and Departamento \\ de Microbiología y Parasitología, Facultad de Farmacia, \\ Universidad de Sevilla, E-41012 Seville, Spain
}

Volume 45, no. 3, p. 464, column 2, lines 3 and 4: "acid is produced from salicin and D-cellobiose, arbutin is hydrolyzed" should read "acid is produced from D-cellobiose but not from salicin, arbutin is not hydrolyzed." 